\title{
CORRIGENDUM
}

\section{Applying recovery biomarkers to calibrate self-report measures of sodium and potassium in the hispanic community health study/study of latinos}

Y Mossavar-Rahmani, D Sotres-Alvarez, WW Wong, CM Loria, MD Gellman, L Van Horn, MH Alderman, JM Beasley, CM Lora, AM Siega-Riz, RC Kaplan and PA Shaw

Journal of Human Hypertension (2017) 31, 860; doi:10.1038/jhh.2017.74

Correction to: Journal of Human Hypertension (2017) 31, 462-473; doi:10.1038/jhh.2016.98; published online 16 February 2017

Since the publication of this article, the authors have noticed that '\%' sign had been omitted after ' 59.5 ' in the abstract section, line 13. Additionally, reference 27 should have been omitted. This omission has led to the following changes:

Statistical analyses section: line 11, reference after (GPAQ) changes from ' 28 ' to ' 27 '

Discussion section: paragraph 2, line 17: reference ' 14,29 ' changes to '14, 28', paragraph 2, line 26: reference ' 30 ' changes to '29' paragraph 2, last line: reference ' 31 ' changes to ' 30 ' paragraph 3, line 10: reference ' 32 ' changes to ' 31 ' paragraph 4, last line: reference ' 33 ' changes to ' 32 ' paragraph 5, last line: reference ' 14 , 29' changes to ' 14,28 ' The authors would like to apologise for these errors. 